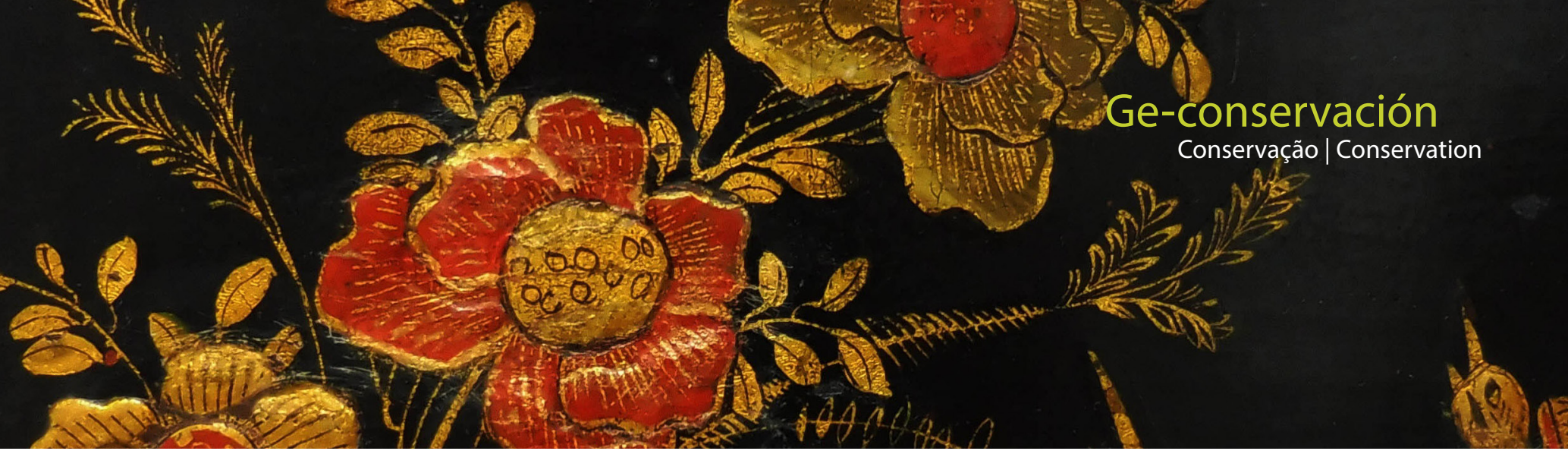

\title{
Una pincelada sobre la técnica de la laca europea
}

\section{Cristina Ordóñez Goded}

Resumen: El artículo describe someramente la técnica de la laca europea, contrastando la información extraída de la documentación histórica (material de archivo, de hemeroteca y tratadística), con los estudios directos y científicos efectuados en obras lacadas y con las publicaciones sobre la materia.

Palabras clave: laca, japanning, arte povera, sandáraca, goma laca, minio, chinerías

\section{A brushstroke on the European lacquer technique}

Abstract: The article describes briefly the European lacquer technique contrasting the information extracted from the historical documentation (material of archiving, old newspapers and technical treatises), with direct and scientific studies carried out in lacquered works and publications on the subject.

Keywords: lacquer, japanning, arte povera, sandarac, gum lac, minium, chineries

\section{Uma pincelada sobre a técnica da laca europeia}

Resumo: O artigo descreve sucintamente a técnica da laca europeia, comparando as informações extraídas da documentação histórica (arquivos, hemeroteca, tratados) com estudos diretos e científicos realizados em obras lacadas e com publicações deste assunto.

Palavras-chave: Laca, japanning, arte povera, sandáraca, goma-laca, mínio, chinoiserie

\section{Introducción}

La laca europea es un procedimiento destinado a la realización de una vasta tipología de obras que surge con la intención de imitar las lacas asiáticas. Los objetos de laca europea más antiguos que se conocen se elaboraron durante la segunda mitad del siglo XVI, a raíz de la llegada a Venecia de las lacas cercano orientales, sobre todo de Persia, Siria o Turquía. En ellos se combinaban los motivos decorativos de esta zona del mundo, como arabescos y vegetales muy estilizados, con elementos tardo- renacentistas. Esta clase de producción artística, que se extendió por Europa hasta mediados del siglo
XVII aproximadamente, consistía fundamentalmente en lujosos y delicados objetos de reducidas dimensiones como arquetas o escritorillos. También se eligió esta técnica decorativa para la ejecución de instrumentos musicales como arpas, clavicordios o espinetas [figura 1].

Por su parte, durante la segunda mitad del siglo XVII surgen métodos de imitación de las lacas extremo orientales en distintos países europeos con sus características propias. Las obras así realizadas, mucho más estudiadas y conocidas que aquellas que se inspiraban en el Cercano Oriente, nacen del interés por las lacas procedentes de China y Japón que fueron llegando a Europa desde finales 
del siglo $\mathrm{XVI}$, gracias a los contactos comerciales entre ambos territorios. Sin embargo, cuando las importaciones de estas obras no consiguieron abastecer la intensa demanda de la clientela europea, unido a los precios desorbitados que llegaron a alcanzar y a la mediocre calidad que iban caracterizando a las lacas chinas de exportación, los artesanos europeos se dispusieron a imitarlas. A este segundo tipo de producción europea de lacas nos referiremos en las siguientes líneas.

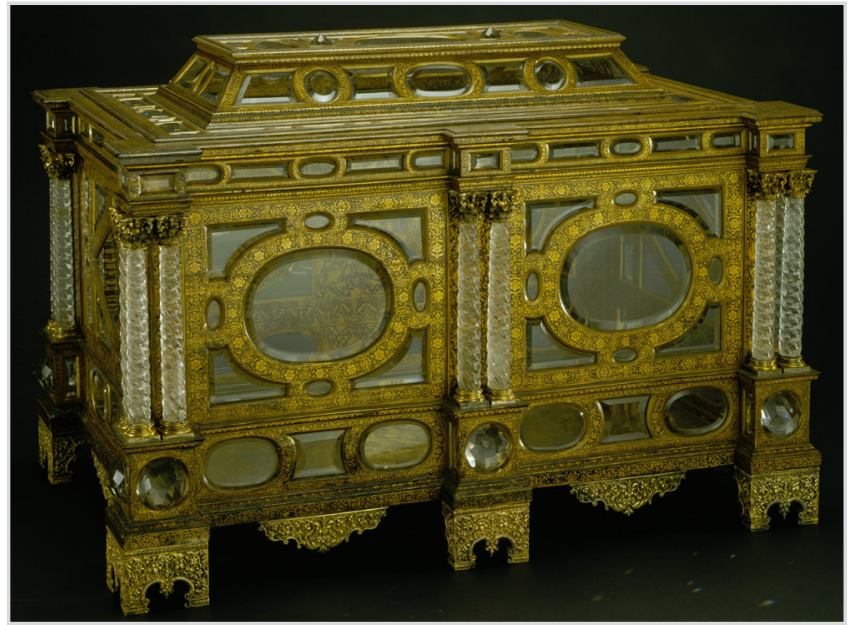

Figura 1.- Arqueta de madera lacada de fondo oscuro con motivos florales dorados, cristal de roca, bronce y plata sobredorada. Venecia. 1600 c. Museo Saint Louis. Missouri. No INV: 346: 1958. 47.9 × 70.8 x 44.5 cm. OMuseo Saint Louis. Missouri. Friends Fund.

\section{Objetivos}

Tres son los principales objetivos del presente artículo: contribuir a la difusión del conocimiento de la laca europea, dado que son escasos los estudios publicados sobre dicho argumento en español; profundizar en los aspectos relativos a su tecnología de elaboración, pues, entre otras cosas, es imprescindible conocer los materiales y métodos utilizados en estas obras para acometer la adecuada conservación y restauración de las mismas y, por último; ofrecer información acerca de la producción española de laca, teniendo en cuenta que los escritos sobre laca europea hasta el momento han obviado su existencia.

La laca europea se aplicaba principalmente a los muebles, a otros elementos domésticos o de uso personal, así como a los carruajes. Con mucha frecuencia se elegía también esta técnica decorativa a la hora de elaborar instrumentos musicales como clavicordios, clavicémbalos, salterios o arpas. Encontramos asimismo laca europea en las salas de algunos de los más importantes interiores europeos, acompañando y completando la decoración parietal a base de lacas orientales, muy de moda desde el siglo XVII.

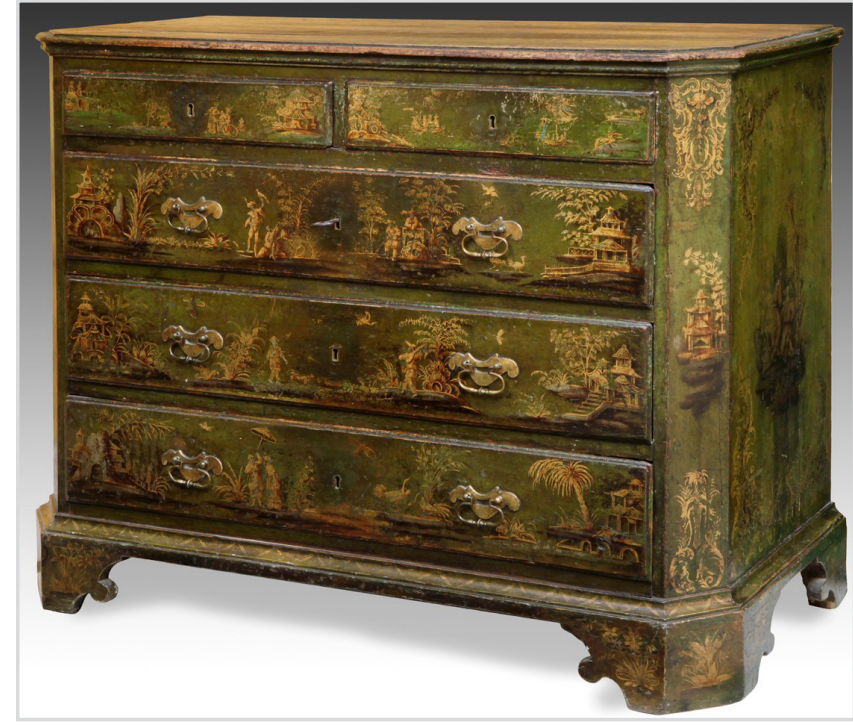

Figura 2.- Cómoda española de laca verde con chinerías. Siglo XVIII. Colección particular @ Cristina Ordóñez Goded.

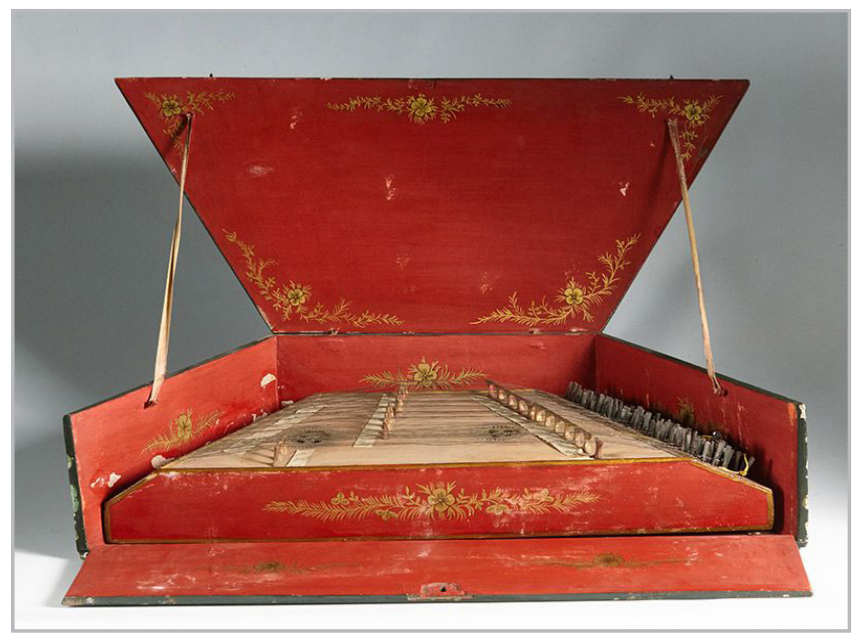

Figura 3.- Salterio italiano de laca rojiza con motivos chinescos. Siglo XVIII. Colección particular. @ Cristina Ordóñez Goded.

Para decorar estos objetos, los artesanos se inspiraron mayoritariamente, sobre todo en los primeros momentos, en los motivos propios de las lacas orientales. Con ellos cubrían las superficies del ajuar doméstico de representación y de los instrumentos musicales más lujosos, con el fin de conferirles un aspecto exótico [figuras $4 a$ y $4 b$ ]. Pero también se recurría a asuntos de carácter local, motivos mitológicos o religiosos, escenas campestres, vistas de ciudades, etc. En los carruajes eran más habituales los temas mitológicos, los fondos con decoración heráldica u otros ornamentos alusivos a los propietarios de los vehículos. Solo ocasionalmente se aprecian chinerías en ellos.

A menudo las chinerías se copiaban o calcaban de las ilustraciones que circulaban por toda Europa en libros de viajes, como por ejemplo el publicado por el viajero holandés Johan Nieuhof (1668), en los tratados de técnicas artísticas, como los diseños de Jean Pillement 
entre 1728-1808 del tratado de Robert Sayer $(1762,1966)$ o los presentes en el de John Stalker y George Parker del año 1668, 1998). Los lacadores también se inspiraron en las imágenes de pintores y grabadores del momento como Nicolás Lancret 1690-1743, Louis Felix de la Rue 1730-1777 o François Boucher 1703-1770, así como en los motivos y escenas de las lacas y de otros objetos asiáticos.

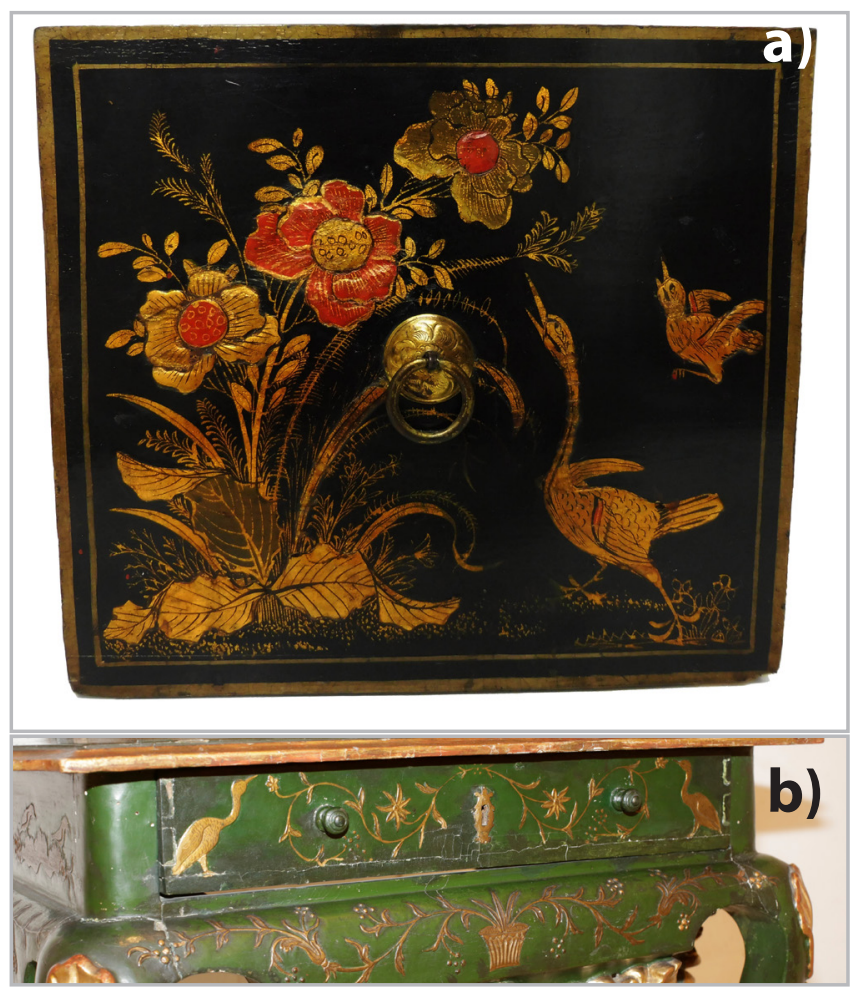

Figuras 4.- 4a. Detalle de las chinerías de un cabinet inglés de laca negra. Siglo XIX. Colección particular. OCristina Ordóñez Goded. Figura 4b. Motivos chinescos en una mesa española de laca verde. Siglo XVIII. Museo de Pontevedra. No INV: 4829. () Museu de Pontevedra.

Los procedimientos de lacado pretendían imitar la luminosidad, transparencia, brillo y profundidad de las lacas orientales, recurriendo a materiales de uso tradicional en Europa, entre otras cosas por los problemas de salud que sufren los occidentales con la manipulación del urushi, la resina que, como sabemos, constituye uno de los principales ingredientes de la laca china y japonesa.

Las lacas europeas eran obras estratificadas que se confeccionaban mediante procedimientos ejecutados con gran paciencia y meticulosidad según las recetas reflejadas en los numerosos tratados que se difundían por Europa desde el siglo XVII. En líneas generales, la técnica consistía en extender sobre el soporte capas sucesivas de materia que se iban puliendo esmeradamente antes de aplicar la siguiente, con el fin de obtener superficies muy lisas.

Aunque la aplicación de la laca podía realizarse sobre diferentes tipos de soporte como piel, metal, cartón piedra o porcelana, la madera era el material más empleado. Por lo general, se recurría a maderas compactas tales como el cedro, el tilo o el haya e incluso a algunas tan preciadas como el nogal, la caoba (Coelho 2012: 213) o el ébano (Ordóñez 2015: 329; Wolsperges 2000: 99). Cuando se hacía uso de esencias con grano menos fino, como el castaño ${ }^{[1]}$ o el roble ${ }^{[2]}$, estas se solían chapear con madera más compacta (Ordóñez 2015: 265, 515; Ordóñez y Rodríguez Simón 2018: 25; Caró, Rizzo, Silverman 2019 : 5-6).

Con frecuencia, sobre el soporte de madera se extendía un aparejo a base de sulfato o carbonato cálcico, disuelto en algún tipo de cola animal y, a menudo, con el añadido de albayalde como carga. En muchas ocasiones la madera recibía previamente una impregnación de cola o de barniz con el fin de conseguir una superficie lo más lisa y uniforme posible sobre la que recibir el aparejo y los sucesivos estratos de materia (Ordóñez 2015: 483, 496). Los adhesivos animales, como la cola de conejo o la de retazos, esta última confeccionada a partir de pieles de cordero o de cabrito (Castro y Velasco 1715, 1947: 1148; Bruquetas 2002: 472; Kroustallis 2008: 122), eran los preferidos por los lacadores y para su empleo debían disolverse al calor de una lumbre sobre carbón, cenizas, arena, etc. El aparejo se aplicaba al objeto en un número variable de estratos que se iban dejando secar, se lijaban y se pulían antes de aplicar el siguiente: ...Para usar de él ha de estar la pieza muy lisa, o aparejada, como si se huviera de dorar de bruñido...(Orellana 1755: 63). El carbonato cálcico se empleaba asiduamente entre los lacadores británicos, mientras que en otros países como España o Portugal se hacía mayor uso del sulfato cálcico (Ordóñez 2015: 336; Caró, Rizzo y Silverman 2019: 5, 6; Coelho 2012: 218). En el mobiliario lacado portugués o de charão, además del aparejo tradicional blanco, se ha constatado la presencia de otros de color verde, rojo, azul, naranja o marrón (Coelho 2012: 221) ${ }^{[3]}$.

El procedimiento de lacado del objeto proseguía con la coloración del fondo que se realizaba, principalmente a través de dos métodos: se aplicaban sobre el aparejo estratos de pintura o bien de barnices coloreados aunque, a menudo se combinaban ambos sistemas. La pintura destinada a conferir una determinada tonalidad a la laca se podía realizar al temple o al óleo. Por su parte, la ejecución del fondo mediante barnices se llevaba a cabo diluyendo distintos colorantes en barnices $y$, normalmente entre las capas coloreadas se extendían otras de barnices incoloros.

Los tonos más empleados en las lacas eran el rojo y el negro, seguidos del azul, el verde y el blanco. La laca roja, muy común en Inglaterra, es muy imitada en España y Portugal, debido a la ingente cantidad de objetos de laca británica, comúnmente llamada japanning que, principalmente durante el siglo XVIII, Ilegaba a la Península Ibérica (Ordóñez 2011: 15; Ordóñez 2015: 89; Ordóñez y Rodríguez Simón 2018: 18) [figura 5]. 


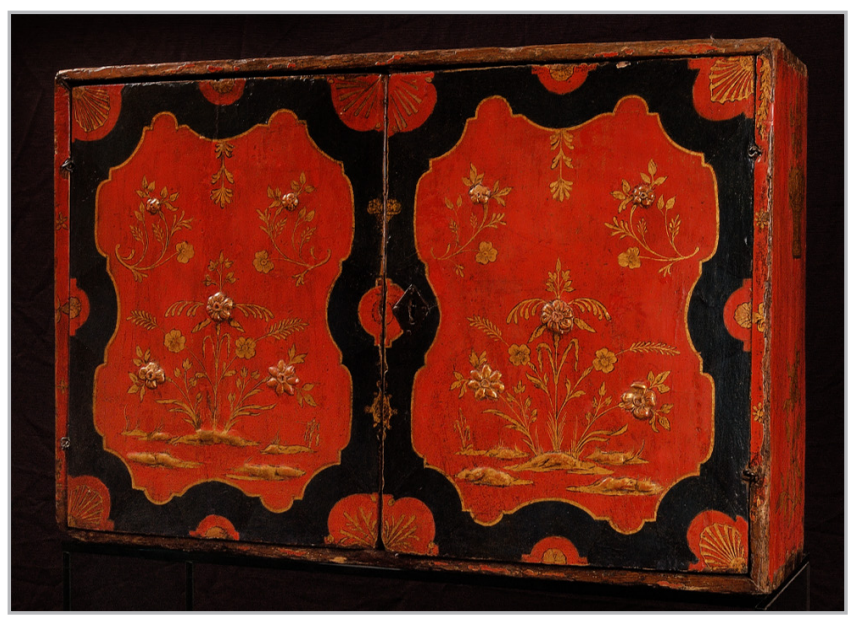

Figura 5.- Contador español de laca roja y negra con chinerías doradas. Colección particular. @ Cristina Ordóñez Goded.

Para la tonalidad roja, era frecuente el uso del bermellón, y del minio. Son numerosas las recetas que encontramos en los tratados para la confección de lacas rojas que mencionan, como la que se transcribe a continuación, estos dos pigmentos combinados en una misma obra: ... Se dan una o dos manos del color que se quiera el fondo. Lo mas general es que sea encarnado con bermellón y parte de minio al óleo ...(Sánchez Caro 1866: 35).

En cuanto a los fondos de color negro se recurría asiduamente al negro humo, al carbón vegetal o al negro de huesos [figura 6]. Encontramos fórmulas en las que se citan estos materiales en los tratados de todas las épocas y países (Ordóñez 2015: 342,343). Así, Palomino aconseja el uso del negro humo en su receta Modo de usar del Barniz de charol: ...y si el charol ha de ser negro, se hará con negro de humo, molido primero en seco en la losa, y desleído en el mismo barniz...(Castro y Velasco 1715, 1947: 747).

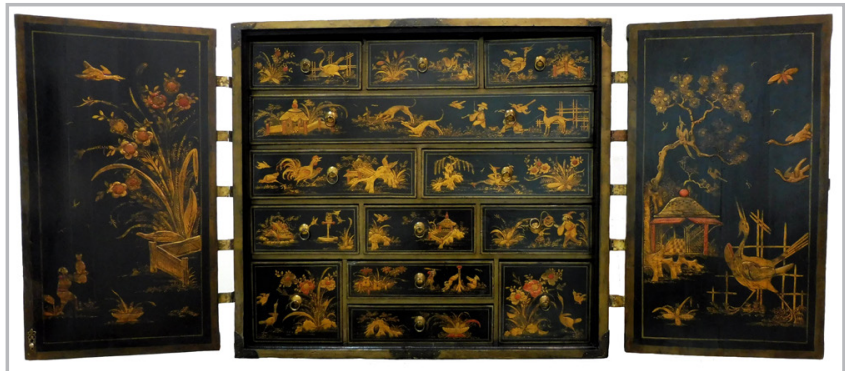

Figura 6.- Cabinet inglés de laca negra. Siglo XIX. Colección particular. $\odot$ Cristina Ordóñez Goded.

Entre los pigmentos más citados en los recetarios para conseguir el color azul en las lacas se encontraban el azul de Prusia y el azul esmalte (Ordóñez 2015: 489). El segundo de ellos gozaba de gran favor por parte de los artesanos británicos de los siglos XVII y XVIII para las obras de japanning, por los satisfactorios resultados que se conseguían con él. Así por ejemplo, Stalker y Parker aconsejan emplear exclusivamente este pigmento para las lacas azules en la receta To make blue Japan (Stalker y Parker 1668, 1998: 22; Helwig 2001: 28). Dossie también lo recomienda aunque lo hace junto a otros pigmentos como el azul de Prusia o el azul verditer (Dossie 1758: 416; Helwig 2001: 28). Conviene señalar que el alto coste de este pigmento constituía un inconveniente para su uso ${ }^{[4]}$.

Otra tonalidad de las lacas fue el blanco, la documentación española nos ofrece numerosos ejemplos de objetos de este color, como el de la siguiente cita procedente del inventario postmórtem de Isabel de Farnesio, redactado en 1746: ...Un Bufete de Charol ${ }^{[5]}$ blanco, cortado en ocho porciones con pie de lo mismo, Matizado de varias figuras y ramos de Papel cortado... ${ }^{[6]}$

Para la ejecución de esta clase de superficies se recurría a distintos colorantes o pigmentos, entre los que destaca el carbonato básico de plomo, también denominado blanco de plomo o albayalde. La intensa tonalidad blanca de esta sustancia, y su elevado poder cubriente, la hacía muy apropiada para los fondos de este color y era la preferida de ciertos artesanos y tratadistas del siglo XVIII como Dossie (Dossie 1758: 416).

Un testimonio del uso de este material en la laca española se localiza en unas memorias de febrero de 1736, firmadas por el aposentador de La Granja de San Ildefonso, Domingo María Sani, sobre los gastos causados para el Oficio de la Furriera de dicho palacio. En él se indica la utilización de cuatro arrobas de albayalde fino:... para azer una Mesa de Charol blanco para la Reyna $N^{a} S^{a} \ldots . .{ }^{[7]}$

Los fondos de las lacas también podían ir dorados, siendo estos muy frecuentes en los carruajes y las sillas de mano (Ordóñez 2015: 641-643) [figura 7]. A menudo se realizaban con panes metálicos dorados o de plata corlada. También se podían dorar los fondos con polvos o fragmentos de pan de oro a imitación de la técnica oriental nashiji-ko, según un sistema denominado en Europa venturina o aventurina. El procedimiento consistía en espolvorear el oro en la superficie húmeda de la laca mediante distintos útiles como pinceles o tubos de bambú cortados diagonalmente con una rejilla, a modo de filtro, en el extremo, cedazos, etc. Dicho método producía un efecto parecido al de la piedra dura denominada venturina ${ }^{[8]}$, de ahí su nombre [figuras $8 \mathrm{a}$ y $8 \mathrm{~b}$ ]. Esta técnica también podía realizarse a base de plata, bronce, cobre o estaño.

La documentación histórica da cuenta del gusto imperante por este recurso decorativo. Así, en 1750, el comerciante francés Lazare Duvaux vendió a Madame Pompadour tres pequeñas mesas lacadas con aventurina...Trois petites tables vernies, en aventurine...(Courajod 1878: 50, 135). Los distintos métodos de aplicación de la venturina se reflejan en determinados tratados europeos, como el de Bernardo Montón de 1734, en la receta titulada Para dar a la madera color de venturina:... Harás el fondo de color obscuro, compuesto de bermellón, sombra, y negro de humo, segun quieras el color mas negro, o mas obscuro, o colorado, 
etc. pondrás mas, o menos de estos colores: estando seco, lo bruñirás, después calentarás la pieza, y luego le pondrás los polvos de venturina passados por cedazo de seda, o por un cañuto, etc. Nota: la pieza debe estar humeda del barniz, para que los polvos se peguen, y después la pulirás... (Montón 1757: 122)

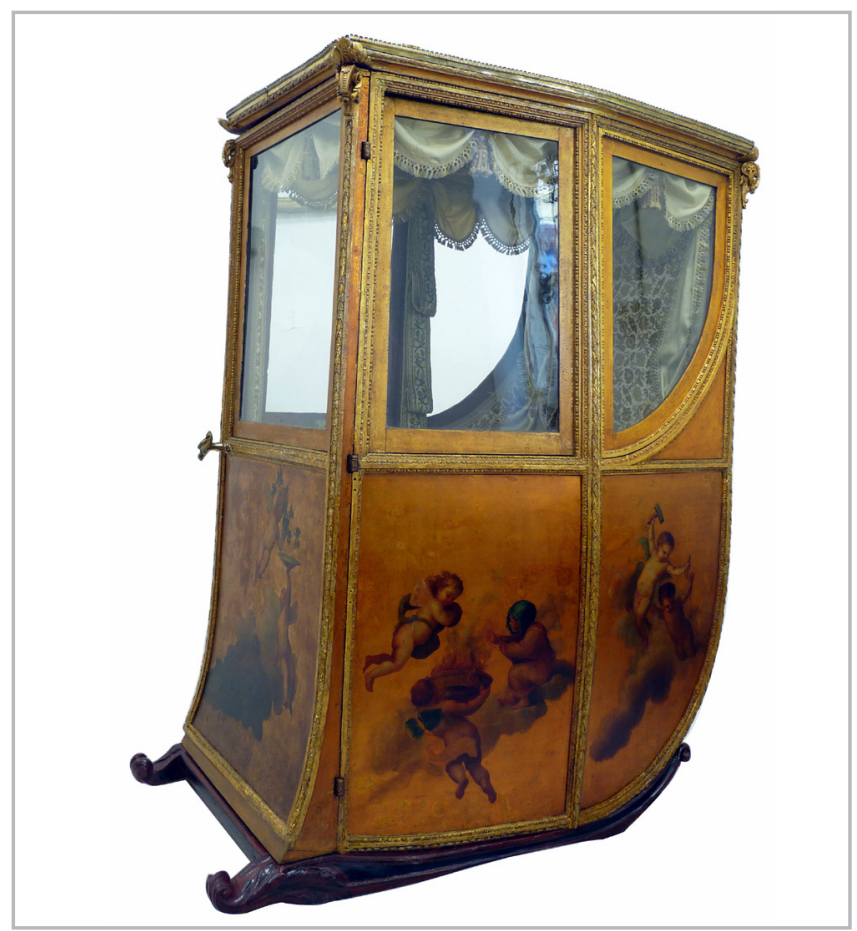

Figura 7.- Silla de manos, probablemente española, de laca de fondo dorado con pinturas alegóricas. Último cuarto del siglo XVIII. Museo de Bellas Artes de Bilbao. № INV: 82/2429. $152 \times 78,5 \times 109 \mathrm{~cm}$. $\odot$ Museo de Bellas Artes de Bilbao.

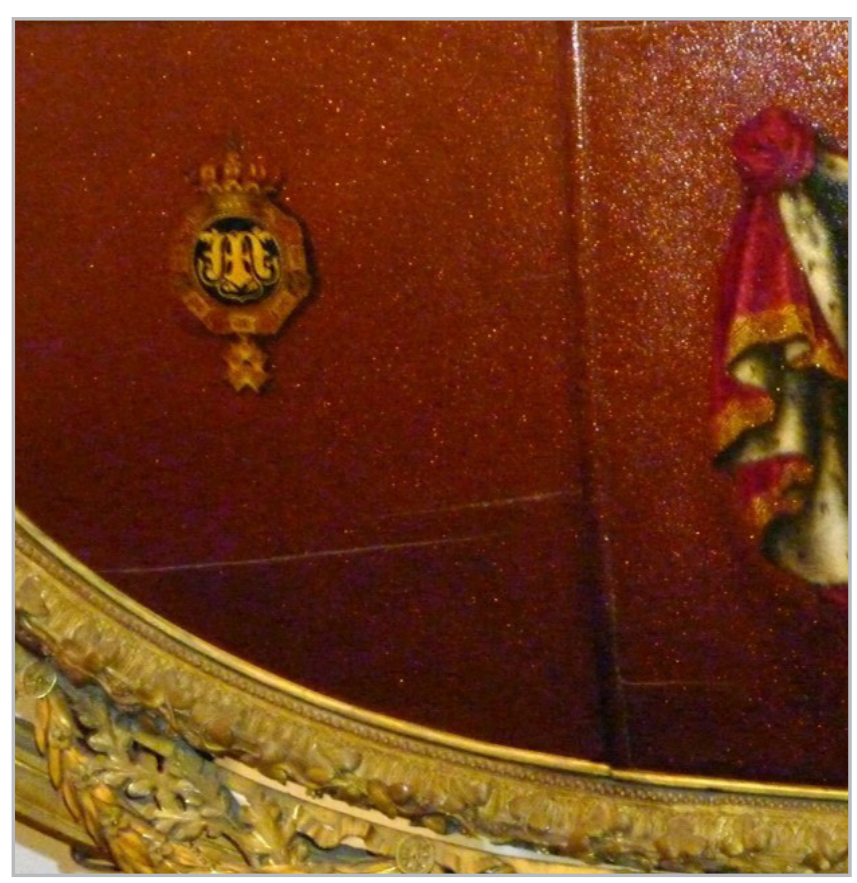

Figura 8a.- Detalle del fondo de venturina dorada de un carruaje alemán del siglo XIX. @Cristina Ordóñez Goded.

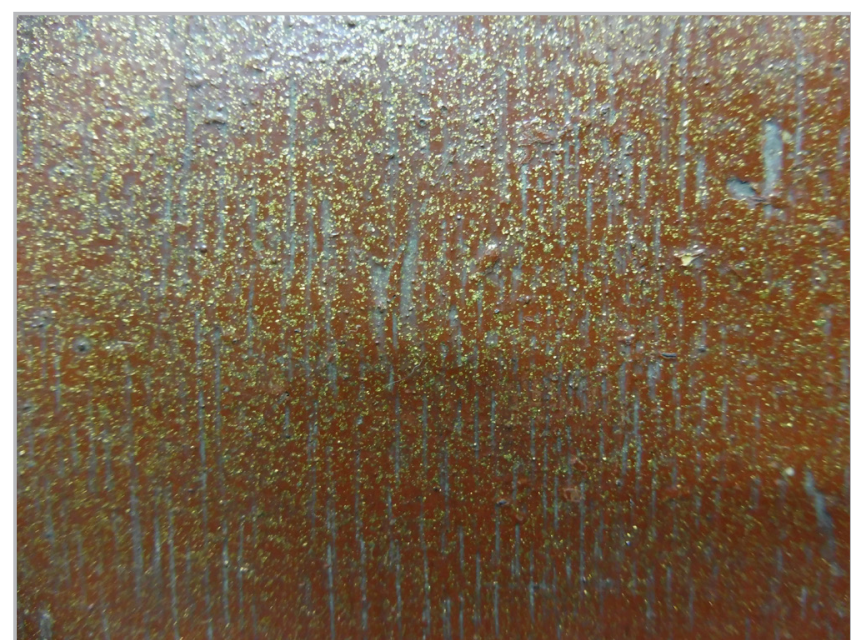

Figura 8 b.-Venturina dorada en el fondo del cajón de un mueble. (c) Museo Nacional de Artes Decorativas.

Con la laca también podían emularse maderas como el palorosa (Santini 2003: 126) o el palosanto, otros materiales como el carey (Stalker y Parker 1668, 1998: 75-76; Huth 1972: 26; Santini 2003: 73-74) $)^{[9]}$, el jaspe, la porcelana ${ }^{[10]}$, el alabastro (Wolvesperges 2000: 111) e incluso técnicas decorativas como la marquetería Boulle (Huth 1972: 94; Santini 2003: 54, nota 143; Morazzoni 1925: 663; Cesari 2004 b: 67).

Con respecto a los barnices transparentes o coloreados que formaban parte de la composición de las lacas, estos consistían por lo general en gomas y/o resinas naturales disueltas en alcoholes, hidrocarburos o aceites. Entre las primeras sustancias se encuentra la goma laca, muy utilizada en España. Así, Palomino recomienda su uso en una receta titulada Barniz de charol, que figura en su tratado de 1715: ...se ha de tomar medio cuartillo de espíritu de vino, y a este se le han de echar tres onzas de goma laca molida, que sea la mejor y más limpia, que hubiere... (Castro y Velasco 1715, 1947: 747)

Otra resina a la que se recurría con asiduidad era la sandáraca, tradicionalmente considerada como la principal materia prima de la laca veneciana ${ }^{[11]}$ y a cuyo uso no faltan recomendaciones en las fuentes españolas, principalmente para las lacas claras. Así, en el volumen titulado Secretos raros de artes y oficios, publicado en 1806, se incluye una receta denominada Otro barniz de la china en la que se aconseja lo siguiente: ...Toma diez yocho onzas de espíritu de vino, seis de sandáraca, dos de trementina fina, y dos de espíritu de trementina: ponlo todo en una botella al sol, removiéndola de hora en hora, y quando lo adviertas muy líquido, pásalo por un lienzo...(Anónimo 1806: 150).

A las sustancias mencionadas habría que añadir otras como el copal, la colofonia ${ }^{[12]}$, el mástic, la trementina o el ámbar, estas dos últimas muy recomendadas por Watin para las lacas (Watin 1776: 293; Webb 2000: 107). Por su parte, el dammar se utiliza únicamente a partir del siglo $\mathrm{XIX}$, que es cuando se inicia su empleo en las técnicas 
artísticas occidentales. Las resinas solían combinarse entre sí para conseguir los resultados deseados. De hecho, es difícil encontrar una receta en la que no figuren varias de ellas. En relación a los materiales destinados a disolver las sustancias sólidas citadas, con el fin de confeccionar los barnices, se recurría a menudo al alcohol etílico o espíritu de vino. A este respecto cabe transcribir parte de una fórmula que recibe el nombre de Barniz de Charol, su uso en el Tratado de barnices y charoles de Orellana (Orellana 1755: 63)...Echa tres onzas de gomalaca molida, limpia, y buena en medio quartillo de espiritu de vino...

La esencia de trementina es otra de las sustancias empleadas en las lacas para diluir resinas, si bien era asimismo utilizada como aglutinante de colorantes y pigmentos. Las mismas funciones eran ejercidas por el aceite, que servía asimismo para el pulimento de los distintos estratos de las lacas o como mordiente para los motivos dorados. El aceite de linaza, que era uno de los más empleados, aparece asiduamente mencionado en la tratadística de los siglos XVIII y XIX. A él se refiere por ejemplo Palomino en una cita que reza así:...Síguese ahora el tratar de los secantes, que se pueden usar a el óleo, de éstos, el más común es el aceite de linaza, cocido con azacón, o litarge, que por otro nombre llaman almártaga de dorar... (Castro y Velasco 1715, 1947: 140). Otros aceites utilizados eran el de espliego, el de nueces, el de amapola o el de oliva. El primero de ellos se cita por ejemplo en el Manual de curiosidades artísticas y entretenimientos útiles de 1831, concretamente bajo el título Barniz de charol que se seca con facilidad: ...Tómense dos onzas de trementina que se lavará muy bien en agua caliente muchas veces, y cuatro onzas de sandáraca; póngase esta al fuego en vasija de barro a propósito, y cuando empieze a humear añádasele la trementina y una onza de aceite de espliego...(Munaiz y Millana 1831: 210). En lo tocante al aceite de oliva, Bonnani sugiere su uso principalmente para el pulimento de los distintos estratos de los barnices (Bonanni 1731: 119). En lo que respecta al aceite de nueces o amapolas, ambos aparecen referidos en recetas de barnices como la que expone a continuación Robert Dossie: ...A very good varnish, free entirily from all brittleness, may be formed by dissoluing as much gum animi, as the oil will take, in old nut or poppy oil...(Dossie 1758: 415).

Con frecuencia, los motivos decorativos, realizados entre los distintos estratos de barniz, eran ejecutados con pan de oro y de plata, según los métodos tradicionales de dorado; al agua y al aceite y solían combinarse en una misma obra panes metálicos de distintas tonalidades, en función de su aleación, al fin de conseguir contrastes de color. Lo mismo sucedía con los elementos bruñidos -que ofrecían un brillo similar al del oro molido- y aquellos sin bruñir o mates ${ }^{[14]}$. La conjugación entre zonas doradas de distinto color y de diferentes intensidades de brillo, permitía efectos estéticos muy logrados y aportaba profundidad a las escenas. Era habitual la combinación entre el oro y la plata en una misma obra, esta última fue muy empleada en las carnaciones de las figuras representadas [figuras 9a, 9b].

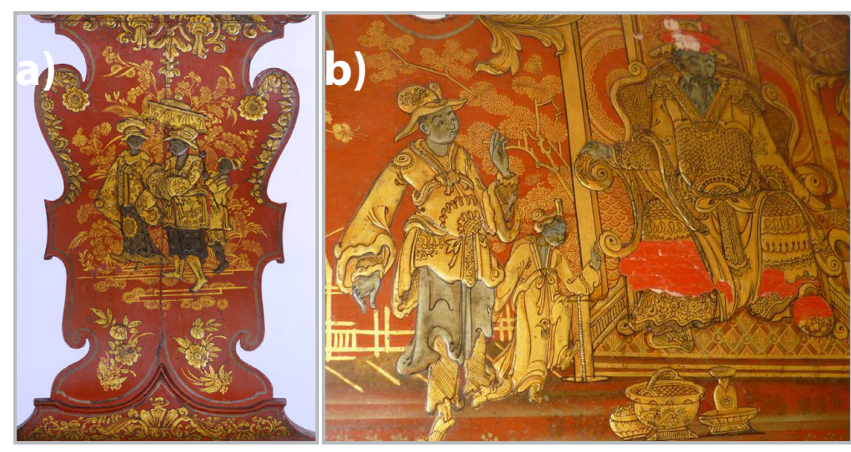

Figura 9 a y b.-Chinerías doradas y plateadas sobre fondo de laca roja. Siglo XVIII.

En el dorado al aceite la hoja metálica se adhería a los motivos, previamente dibujados, sobre la laca húmeda o bien mediante un mordiente aplicado exclusivamente en el motivo a dorar que podía consistir en un barniz, un aceite o un adhesivo como la goma arábiga o la cola de pescado. A la hora de dorar los motivos al aceite, ciertos autores recomendaban teñir el mordiente sobre el que se debían fijar los panes metálicos, con el fin de delimitar y reconocer el lugar concreto en el que esta acción debía llevarse a cabo. Watin y Salker y Parker sugerían hacerlo de rojo con bermellón (Watin 1776: 295; Stalker y Parker 1668, 1988: 37). Sin embargo, era asimismo habitual utilizar mordientes amarillos, negros (Caró, Rizzo y Silverman 2019:10) o blancos, estos últimos principalmente para el plateado ${ }^{[15]}$.

Para la ejecución de los motivos decorativos dorados y plateados podía asimismo recurrirse a un sistema que en algunos textos se denomina "pintura de oro" o "de plata". Consistía en la aplicación, a pincel, de un líquido elaborado con polvos metálicos aglutinados en sustancias como la goma arábiga, distinto tipo de barnices, colas o aceites. Este procedimiento no debe confundirse con el de la venturina, a pesar de que en ocasiones recibía la misma denominación. Por su parte, se empleaba el término estañado cuando se aplicaban soluciones a base de estaño líquido. La pintura de oro o de plata se utilizaba con frecuencia para enriquecer determinadas superficies mediante perfiles dorados, plateados o estañados. Cuando el polvo metálico utilizado para aplicar la pintura de oro se confeccionaba con diferentes metales entre los que no se incluía el oro (cobre, aluminio, estaño, latón, bronce, cinc, plomo, etc), esta sustancia podía recibir el nombre de purpurina ${ }^{[16]}$ y su uso en el dorado se cita en las fuentes históricas desde el siglo XVIII. Lo encontramos por ejemplo en Palomino, dentro de la definición del verbo "broncear", que el autor incluye en el glosario de términos de su tratado de 1715:... Imitar a el bronce con la purpurina, sobre mano de color mordiente, a el óleo... (Castro y Velasco 1715, 1947: 1146).

Las superficies doradas se podían asimismo "broncear", mediante veladuras de barniz de tonalidad parda o anaranjada, con el fin de que adoptaran el aspecto del bronce "dorado de molido" (Coelho 2012: 260; Bartolomé García 2004: 17; Munaiz y Millana 1831:215), para producir 
un efecto de profundidad (Caró, Rizzo y Silverman 2019:10), para dar color a las carnaciones de los personajes orientales, etc.

Las técnicas del estofado y del estarcido no son infrecuentes en las lacas europeas (Ordóñez 2015: 372; Coelho 2012: 237). Con ellas podía obtenerse una amplia gama de diseños, tanto abstractos como figurativos. Entre las decoraciones abstractas destacan las de retícula ${ }^{[17]}$, circunscritas en reservas de formas variadas e inspiradas en las de las lacas extremo orientales [figura 10]

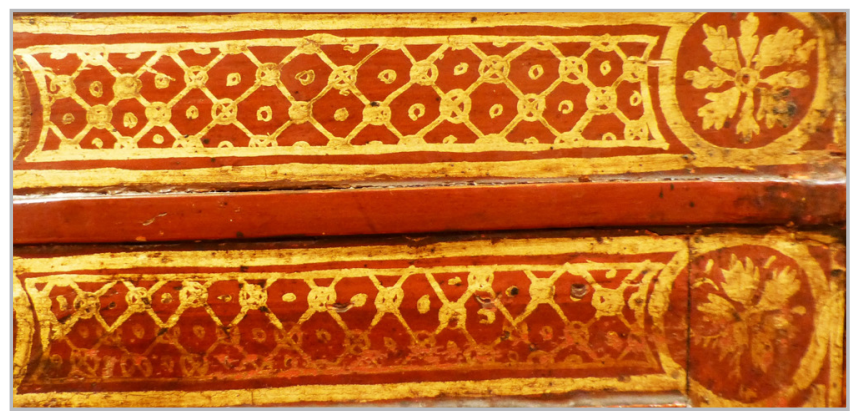

Figura 10.- Retículas doradas realizadas según la técnica del estarcido.

Los elementos decorativos podían perfilarse de negro ${ }^{[18]}$ o de otros tonos como el verde oscuro, cuyo uso se ha constatado en lacas portuguesas (Coelho 2012: 257). A menudo se ejecutaban en relieve [figuras $11 \mathrm{a}, \mathrm{b}, \mathrm{c}$ ] y uno de los modos de conseguirlo era mediante la aplicación de estucos, confeccionados con sustancias de diferente naturaleza. Bonanni propone varias recetas para la ejecución de estos estucos o material de relleno, como aquel a base de blanco de plomo, bol de Armenia y minio

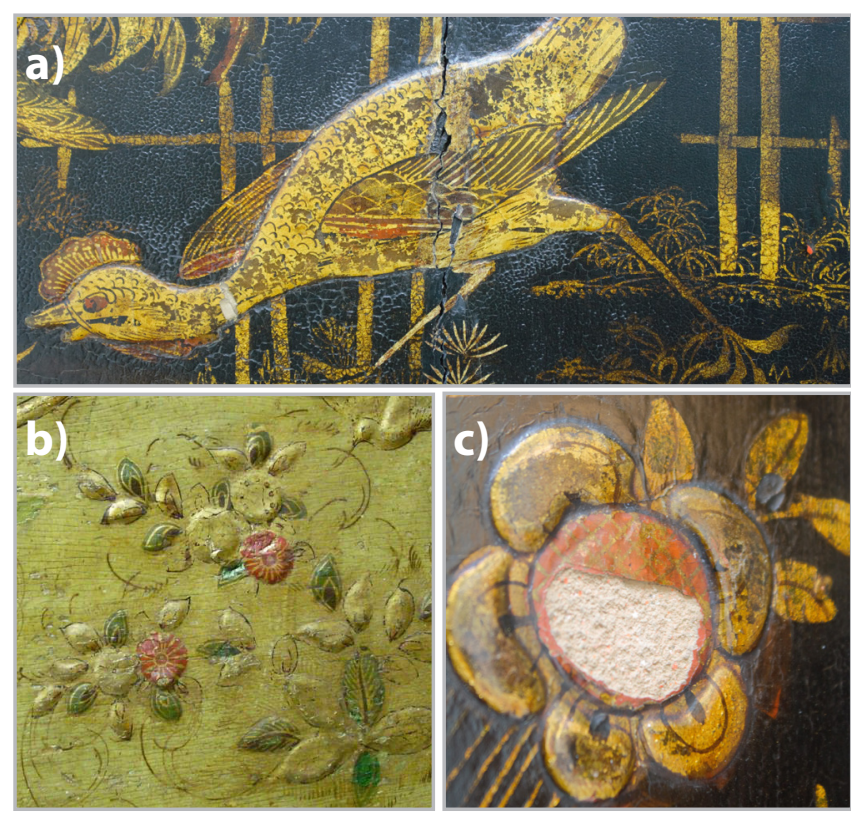

Figura 11 a,b, c.- Motivos con relieve en muebles lacados. El motivo de la fig. 11 c. presenta una laguna en la que se percibe el material de relleno.

aglutinados con cola animal (Bonanni 1731: 108). Por su parte, Watin recomienda la mezcla de carbonato cálcico, el pigmento tierra de sombra y un barniz graso (Watin 1776: 296) ${ }^{[19]}$. Stalker y Parker aconsejan el uso de una pasta confeccionada con goma arábica, carbonato cálcico y bol de Armenia (Stalker y Parker 1668, 1998: 32, 34). Esta misma receta aparece en el tratado de Dossie (Dossie 1758: 422; Helwig 2001: 28). Según ciertos autores, a este tipo de estucos se podía añadir arena o polvo de madera (Edwards 1964: 329; Jacobson 1993: 46) [figuras 12, 13].

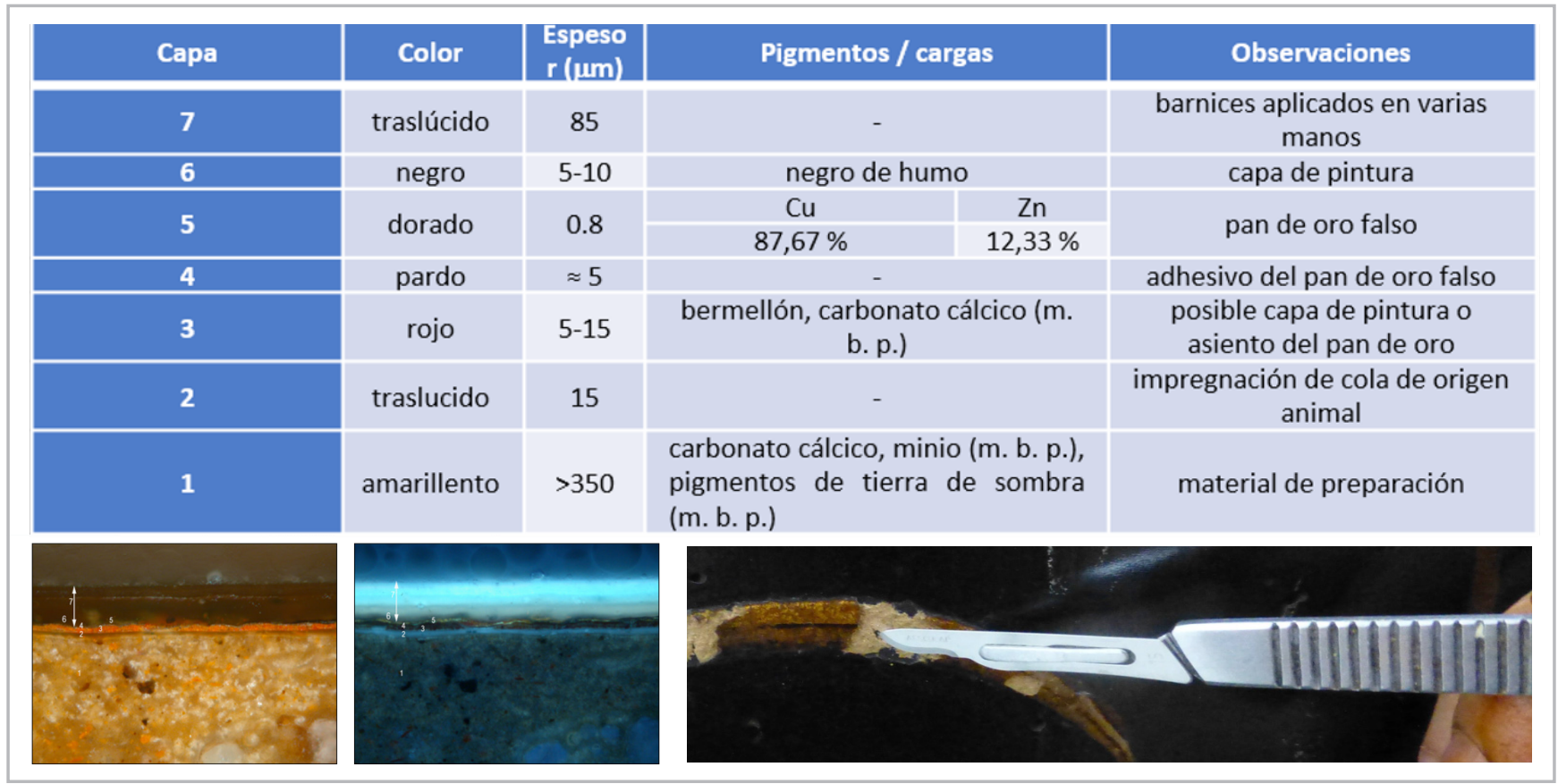

Figura 12. Toma de muestra del material de relleno de un motivo con relieve y estratigrafía en donde se ve la composición del mismo en el estrato 1: carbonato cálcico, minio y pigmentos de tierra de sombra. Debajo: imágenes obtenidas al microscopio óptico de la sección transversal de la muestra, la de la derecha iluminada con luz UV. Cabinet inglés. Siglo XIX (Fig. 6). Laboratorio Arte Lab (Madrid). 


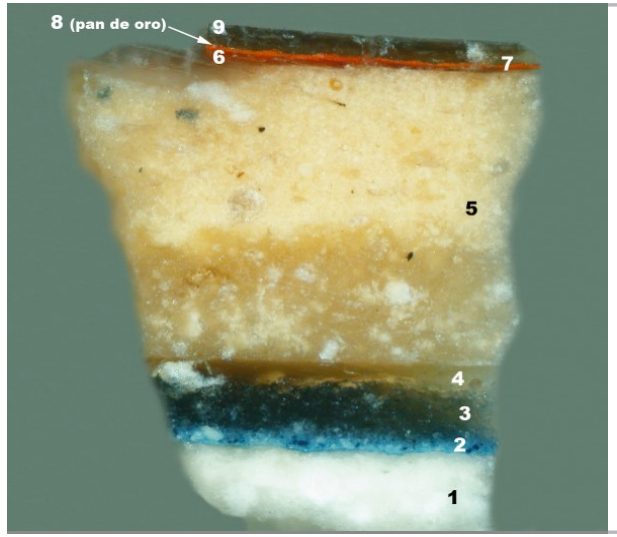

\begin{tabular}{|c|c|c|c|c|}
\hline Capa & Color & $\begin{array}{c}\text { Espesor } \\
(\boldsymbol{\mu m})\end{array}$ & Pigmentos/cargas & Observaciones \\
\hline 9 & pardo & 80 & - & $\begin{array}{l}\text { barniz aplicado en } \\
\text { varias manos }\end{array}$ \\
\hline 8 & dorado & 0,9 & oro (Au) & pan de oro \\
\hline 7 & rojo & 10 & bermellón, óxido de hierro & capa de pintura $[1]$ \\
\hline 6 & pardo & 10 & - & barniz \\
\hline 5 & blanco & 530 & carbonato cálcico, albayalde (b. p.) $)^{[2]}$ & material de relleno \\
\hline 4 & pardo & 30 & - & barniz \\
\hline 3 & azul & 70 & azul esmalte, albayalde, tierras (m. b. p.) & capa de pintura \\
\hline 2 & azul & 30 & azul de Prusia, albayalde, silicatos & capa de pintura \\
\hline 1 & blanco & 120 & carbonato cálcico & aparejo \\
\hline
\end{tabular}

Figura 13.-Estratigrafía de la micromuestra del material de relleno de un motivo con relieve en un reloj inglés del siglo XVIII. Este material aparece en el estrato 5 y se compone de carbonato cálcico y albayalde, este último material en una baja proporción. Laboratorio Arte Lab (Madrid).

Para la decoración de la laca se podía recurrir a otros materiales como el nácar, el metal macizo, el papel, o más raramente, la cáscara de huevo. Con respecto al nácar, las cualidades estéticas de este material lo hacían propicio para múltiples aplicaciones. A veces se utilizaban piezas irregulares de reducido tamaño que se esparcían sobre la superficie a imitación de una de las modalidades decorativas de la laca japonesa denominada mijinmaki (Kawamura 2013:441). En ocasiones servía para configurar cenefas o franjas ornamentales que delimitaban reservas con escenas, elementos figurativos, retículas, etc. En el siglo XIX el nácar contribuyó a caracterizar un estilo de muebles II Imperio de laca negra con chinerías, flores y otras formas orgánicas doradas y pintadas sobre soportes de madera y/o de "cartón piedra"[20] [figura 14]. En este género de producción destacó la empresa británica Jennens \& Bettridge, establecida en Birmingham entre 1815 y 1864.

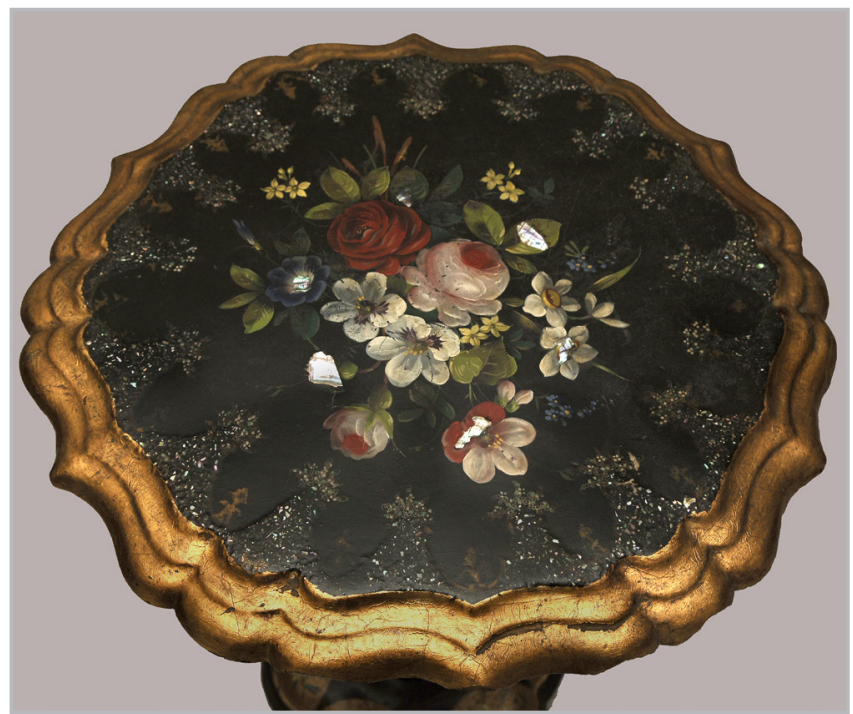

Figura 14.-Tablero de mesa lacada de fondo negro sobre soporte de "cartón piedra" y madera con aplicaciones de nácar y pintura al óleo. Siglo XIX. Museo Nacional de Artes Decorativas. № INV 17787. @ Museo Nacional de Artes Decorativas.
En cuanto a las decoraciones con cáscara de huevo, estas llegaron a tener gran fortuna en el siglo $\mathrm{XX}$, dentro del movimiento Art decó y a imitación del Tamago-no-mijinmaki japonés, un método que consistía en esparcir, sobre la superficie de la laca, partículas irregulares de dicho material.

El papel, además de utilizarse según la modalidad del "cartón piedra" antes descrita, se empleaba según el procedimiento del arte povera también denominado laca povera, laca contraffata o decoupage, que consistía en la decoración de los objetos lacados mediante recortes de grabados coloreados (Van Hauwermeiren-Echement 2008: $3,4)$. Dicha técnica, de tradición occidental, se desarrolló en las lacas europeas principalmente durante el siglo XVIII, con la intención de responder, con costes menores, a la enorme demanda europea de piezas lacadas y adquirió gran protagonismo en Venecia ${ }^{[21]}$ [figuras15a, 15b]. Los grabados para el arte povera se difundieron desde famosos talleres de grabado como el de la familia Remondini de Bassano o los de Marco Ricci 1676-1730, Giuseppe Zaiss 1709- 1784, Francesco Zucarelli 1702-1788, Teodoro Viero 1740-1819, Giuseppe Wagner 1706-1780 o Robert Sayers 1725-1794 ${ }^{[22]}$, en ocasiones mediante la venta ambulante (Cesari 2004 a: 40; Cesari 2004 b: 67-71; Zotti Minci 1994: 91-111; Di Castro 1983: 755), por lo que es difícil establecer la nacionalidad de las obras así decoradas ${ }^{[23]}$.

En los siglos XVIII y XIX fueron muchos los diletantes que practicaron la laca povera (Huth 1972: 65, 72; Webb 2000: 140). De hecho, Sayers, en su publicación The Ladies Amusement or the whole art of japanning made easy de 1762, proporcionó diseños para aficionados (Sayers 1762, 1966: 25; Webb 2000: 140) ${ }^{[24]}$. Entre los motivos de los grabados destacan los orientales, los de tipo pastoril, y no faltan las escenas cinegéticas, teatrales, musicales, devocionales o aquellas en las que aparecen personajes desempeñando oficios variados. También encontramos representaciones aisladas de animales o flores. Los paisajes, las escenas y los personajes de la "Commedia dell' Arte" italiana suelen ser asimismo habituales. 

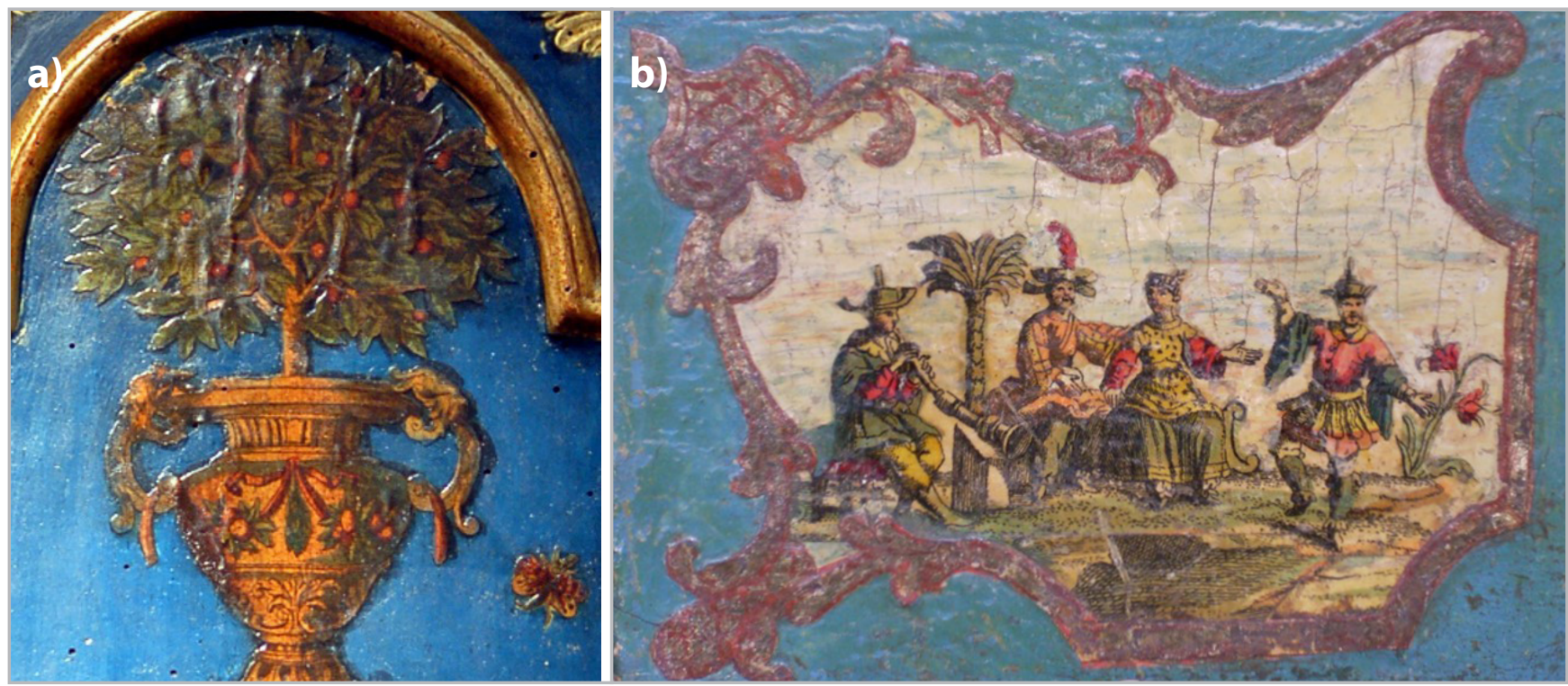

Figura 15 a, b.- Recortables de papel en muebles de arte povera.

Los recortables se fijaban a las superficies lacadas según distintos métodos: podía hacerse directamente sobre la laca húmeda o también mediante otras sustancias mordientes como aceites, barnices, adhesivos como la cola de pescado, gomas como la arábiga, etc (AAVV 2006: 98-99; Watin 1776: 281-283; Lorenzetti 1938: 15). Finalmente, la obra recibía diversas manos de barniz lo que, además de aportar el lustre requerido, servía para proteger los grabados. En la documentación española, los ejemplares elaborados según esta técnica vienen descritos comúnmente con expresiones como "papeles cortados" u otras similares (Ordóñez 2015: 378-379). Sirva de ejemplo la siguiente cita extractada de una relación de bienes pertenecientes a la reina Isabel de Farnesio del Palacio de San Ildefonso de 1774... Una Messa de Charol blanco con su Naveta, y llave con pies de Cabra, toda guarnecida de difer. ${ }^{\text {tes }}$ Arvoledas Caserias, y Figuras de papeles cortados y guarniciones dor. ${ }^{\text {das }}$ tiene dos pies y me. ${ }^{\circ}$ de alto; dos de ancho $y$ tres de largo... ${ }^{25]}$

Una vez aplicados todos los estratos de materia en las lacas y realizada la decoración, las capas finales de barniz se iban puliendo y dejando secar previamente a la extensión del siguiente, con el fin de conseguir una superficie perfectamente lisa, algo necesario para obtener el brillo final deseado. Los últimos estratos de barniz se pulimentaban con enorme meticulosidad, para lo cual se empleaban distintos materiales, como el trípoli o polvo de pizarra, la piedra pómez pulverizada, la raíz de alkanet, el cristal pulverizado, el polvo de esmeril, el abrasivo vegetal conocido como "cola de caballo" (Agricola 1789: $152-153)^{[26]}$ o la piel de tiburón, unidos, en ocasiones, a determinados aceites. Otro producto abrasivo que se recomienda en la literatura técnica para esta tarea es la harina. Bonanni señala que dicho material contribuía a la eliminación del exceso de grasa, tras haberse tratado previamente la superficie, con trípoli y aceite de oliva (Bonanni 1731: 119).

\section{Conclusiones}

A modo de conclusión podemos constatar que la metodología de estudio que concilia la investigación histórica y los análisis científicos, el conocimiento empírico y la incorporación progresiva de los resultados de las investigaciones que van surgiendo en torno a este tema, ofrece una valiosa información sobre las técnicas de ejecución de esta rica parcela de bienes culturales hasta ahora poco e inmerecidamente transitada en nuestro país. Con este articulo esperamos haber contribuido a despertar interés sobre ella y a incentivar su estudio. De hecho, el conocimiento en profundidad de estas obras, tan delicadas como complejas a nivel tecnológico, puede evitar tratamientos irreversibles como algunos que lamentablemente han recibido a través del tiempo.

\section{Agradecimientos}

Museo de Saint Louis (Missouri); Museo de Pontevedra; Museo Nacional de Artes Decorativas (Madrid); Museo de Bellas Arte de Bilbao;Arte-Lab (Madrid)

\section{Notas}

[1] Muy utilizado en Portugal, sobre todo en el Norte (Coelho 2012: 212).

[2] Madera autóctona de Inglaterra muy empleada en este país como soporte de las lacas.

[3] Conviene señalar que a menudo se eludía el aparejo por diversas circunstancias, algo que se refleja tanto en la documentación histórica como en los estudios científicos llevados a cabo en obras lacadas (Ordóñez 2015: 336; Caró, Rizzo y Silverman 2018: 5-6. 
[4] De los treinta y siete estudios científicos llevados a cabo en mi tesis doctoral solo he encontrado este azul en las piezas correspondientes a dos relojes ingleses del siglo XVIII (Ordóñez 2015: 487-493).

[5] Se trata de uno de los términos más utilizados en España en el pasado para designar la técnica decorativa de la laca (Ordóñez 2015: 121-125).

[6] AGP. AP. San Ildefonso. Caja 13568. (Inventario General de Pinturas, Muebles y otras Alhajas de la Reina Ntra. S. ${ }^{r a} q^{e}$ tiene en el Palacio del R'. Sitio de San Ildephonso, ejecutado de orden del Rey Nuestro señor en el año de 1746).

\section{[7] AGP. AP. San Ildefonso. Caja 13554.}

[8] Una variedad del cuarzo con placas de mica que producen unos reflejos brillantes dorados conocidos como efecto aventurinado ( Kroustallis 2008: 413).

[9] Un ejemplo de imitación del carey, puede verse en un cabinet lacado inglés de hacia 1690-1700 del Museo Victoria \& Albert de Londres. No Inv: W. 20:1 a 16-1959. http://collections.vam.ac.uk/ item/O53113/cabinet-on-stand/ (consulta 20.4. 2019).

[10] A principios del siglo XVIII el artífice alemán Schnell se especializó en realizar jarrones de madera lacada a imitación de los de porcelana (Huth 1972: 74; Ordóñez 2015: 98).

[11] Lo que está aún por ser verificado.

[12] Esta resina es la que aparece en mayor proporción formando parte de los barnices en los objetos de laca europea analizados (Ordóñez 2015: 550, 661).

[13] El término goma anime podía referirse a una variante del copal, también a una resina que exuda un árbol tropical americano llamado Hymen[ae]a courbaril, muy empleada en la confección de barnices (Kroustallis 2008: 247, 248).

[14] Watin aconseja combinar ambos sistemas en función de los elementos a representar (Watin 1776: 301-303).

[15] En el tratado de Sánchez Caro de 1866 se aconseja, además, dar una mano de cola de pescado sobre el estrato de barniz, previamente aplicado a la superficie del objeto, quedando excluidas de esta acción las zonas delimitadas para ser doradas. De esta manera, una vez seca la cola, se evitaría que el polvo o los fragmentos de metal espolvoreado cayeran fuera de las mismas (Sánchez Caro 1866: 36).

[16] La purpurina podía obtenerse tanto en estado sólido como líquido al aglutinarse con distintos barnices o adhesivos. En la actualidad también se denomina purpurina a determinadas sustancias sintéticas, sólidas, líquidas o pastosas (Kroustallis 2008: 366-367).

[17] Estas retículas, muy habituales en el japanning, solían conocerse como latticework, strapwork o diapper pattern entre otras denominaciones.
[18] Para ello se utilizaba frecuentemente el carbón vegetal (Ordóñez 2015: 510, 561) o el negro humo (Coelho 2012: 257).

[19] Este material de relleno es el que más se acerca al identificado en los studios de determinados objetos lacados (Dundsmore 2007: 70; Ordóñez 2015: 481-482). Resultados similares se han evidenciado en la composición del material de relleno amarillento de un cabinet británico del siglo XIX restaurado recientemente en Arcaz (2018). Tras el análisis de una micromuestra tomada del mismo se ha constatado la existencia de carbonato cálcico, minio y tierra de sombra, con un espesor de 270 micras.

[20] El "cartón piedra" o papier maché podía realizarse mediante pasta de papel que se dejaba secar y después se moldeaba, o bien con láminas superpuestas de papel. A veces este tipo de soporte descansaba sobre otro de madera.

[21] En Venecia los grabados eran realizados por los miniadori, los artesanos pertenecientes al arte dei depentori (Santini 2003: 2554, nota 143; Morazzoni 1925: 663; Cesari 2004 b: 67).

[22] Calcografía de este artesano se localizaba en Londres. También se conocen los nombres de famosos artífices que individualmente ejecutaron grabados para el arte povera en distintos lugares, como el lorenés Jacques Callot en Florencia entre 1592-1635, Martin Engelbrecht 1684-1756 en Augsburgo, o Louis Crépy 1680-1746 en París ( AAVV 2006: 98; Huth 1972: 65; Fernández Martín 2009: 6-7).

[23] Además, los Remondini plagiaron los diseños de ciertas calcografías de Augsburgo, Roma, el Tirol o Inglaterra y en 1780, varios artesanos abandonaron dicha tipografía, se dispersaron por Europa y, a consecuencia de ello, se multiplicaron las réplicas de sus grabados en varios países (Cesari 2004 b: 71; Infelisi 1999; Chiesura 2015: 5,13).

[24] Según Huth, en 1780 el cronista de Augsburgo Paul von Stetten señala a España y Alemania como los países en los que el arte povera era más común entre los aficionados (Huth 1972: 62).

[25] AGP. AP. San Ildefonso. Caja 13568.

[26] La cola de caballo es una pequeña planta denominada equisetum hyemale. Carece de hojas y se compone de una simple caña parecida al bambú. Crece en los suelos arenosos, de donde absorbe sílice que deposita en su superficie, con lo que se convierte en algo parecido a la lija. Fue muy utilizada para pulir las superficies de laca japonesa (Ordóñez 2004: 5).

\section{Referencias}

AAVV. (2006). European furniture in the Metropolitan Museum of Art. Higlights of the Collection. The Metropolitan Museum of Art. Yale University Press. Londres.

AGRICOLA, F. (1788). Trattenimenti Sulle Vernici, ed altre materie utili, e dilettevoli sparse nelle opere di molti accreditati autori, Particolarmente nel Trattato assai stimato del P. Filippo Bonanni., 
Raccolti, ed ordinati da Francesco Agricola. In Ravenna nella Stamperia Roveri presso I Fratelli Fava.

ANÓNIMO. (1806). Secretos raros de artes y oficios. Imprenta de Villapando. Madrid.

BARTOLOMÉ GARCÍA, F. R. (2004). “Terminología básica de técnicas y materiales de la policromía". Akobe: restauración y conservación de bienes culturales, Zutabe: 17.

BONANNI, F. (1731). Trattato sopra la vernice detta comunemente cinese. Roma.

BRUQUETAS, R. (2002). Técnicas y materiales de la pintura española en los siglos de oro. Fundación de apoyo a la Historia del Arte Hispánico. Madrid.

CARÓ, F., RIZZO, A., SILVERMAN, C. (2019). An Investigation of Eighteenth -Century English Red Japanned Furniture in the Collection of the Metropolitan Museum of Ar". Nueva York. Studies in Conservation: 5-10. https://www.tandfonline.com/ doi/abs/10.1080/00393630.2018.1563356 (consulta 1-3-2019)

CASTRO Y VELASCO, A. A. P. (1715). El museo pictórico y escala óptica. Indice de términos privativos de la pintura. (Ed. cons. Aguilar. Madrid 1947). Vol 1.

CESARI, P. (2004 a). "Storia del mobile Picto in Italia" en AAVV., Mobili Dipinti. Ícaro edizioni. Módena: 40.

CESARI, P. (2004 b). "La lacca povera e la calcografía dei Remondini" en AAVV., Mobili Dipinti. Ícaro edizioni. Módena: $67,71$.

CHIESURA, C. (2015). Tra iconografía e comercio: i Remondini e le stampe devozionali. Tesi di Laura. Universitá Ca' Foscari. Venezia.

COELHO, D. (2012). O mobiliário pintado em Portugal do século XVIII. Materiais, técnicas e estado de conservação. Tesis Doctoral. Universidad Católica portuguesa.

COURAJOD, L. (1878). Livre Journal de Lazare Duvaux. 17481758, Vol. 2. Sociéte des Bibliophiles François. París.

DI CASTRO, D. (1983). "Lacca" en AAVV., Enciclopedia delle Arti Decorative. Vol. 2. Coord. Álvar González Palacios. Fabbri, Milán.

DOSSIE, R. (1758). The hand maid to the Arts. J. Nourse. Londres.

DUNSMORE , A. (2007). "The Giles Grendey Daybed in the National Gallery of Victoria". Proceeding of the Inaugural Australian Furnishing History Symposium, Canberra, Greg Peters and Jun Kennedy. Woodbridge, Suffolk: 7

EDWARDS, R. (1964). The shorter dictionary of English furniture from the middle ages to the late georgian period. Spring book. Londres.
FERNÁNDEZ MARTíN, M. (2009). “A propósito de unos muebles de lacca povera en una colección sevillana". Actas del Congreso Internacional Imagen Apariencia. Murcia.

JACOBSON, D. (1993). Chinoiserie. Phaidon. Nueva York.

HELWIG, K. (2001). “Materials Analysis of a Japanned Long Case Clock". Journal of the Canadian Association for Conservation Vol. 26. Otawa: 1-8. https://www.cac-accr.ca/wp-content/ uploads/2018/12/Vol26 doc4.pdf (consulta 4. 5. 2018).

HUTH, H. (1972). Lacquer of the West. The history of a craft and an industry $1550-1950$. The University of Chicago Press. Chicago/ Londres.

INFELISE, M., MARINI, P. (1990). Remondini. Un Editore del Settecento. Electa. Milán.

KAWAMURA, Y. (2013). “Laca japonesa urushi de estilo namban en España. Vías de su llegada y destinos en AAVV., Lacas Namban. Huellas de Japón en España. IV Centenario de la Embajada Keicho, Ministerio de Educación, Cultura y Deporte/ Fundación Japón. Madrid.

KROUSTALLIS, S. K. (2008). Diccionario de materias y técnicas. Ministerio de Cultura. Madrid.

LORENZETTI, G. (1938). Lacche veneziane del Settecento. Cat. Exp. Carlo Ferrari. Venecia.

MONTÓN, B. (1757). Secretos de Artes Liberales y mecánicas recopiladas y traducidas de varios y selectos authores, que tratan de phisica, pintura, arquitecura, óptica, chimica, doradura y charoles con otras varias curiosidades ingeniosas. Oficina de los Herederos de Martínez, Pamplona.

MORAZZONI, G. (1925). Lacche veneziane del secolo XVIII. Dédalo. Milán, Roma.

MUNAIZ y MILLANA, R. (1831). Manual de curiosidades artísticas y entretenimientos útiles. Impresor Francisco Sánchez. Reus.

NIEUHOF, J. (1668). Legatio batavica ad magnum Tartariæ chamum Sungteium, modernum Sinæ imperatorem. Jacob Van Meurs. Amsterdam.

ORDÓÑEZ, C. (2004). "Dos maestros de la talla en madera. Grinling Gibbons y Andrea Brustolon" en AAVV., Curso sobre mobiliario antiguo. GEIIC. Madrid: 5. http://www.geiic. com/files/Publicaciones/Dos maestros talla madera.pdf8 (consulta 1. 12. 2018).

ORDÓÑEZ, C. (2011). "Japanning en España. Un lote de muebles de laca color escarlata realizado por Giles Grendey", Estudi del moble, n 14: 15.

ORDÓÑEZ, C. (2015). De lacas y charoles en España. Siglos XVI$X I X$. Tesis doctoral. UCM. 
ORDÓÑEZ, C., RODRIGUEZ SIMÓN, L. R. (2018). “Análisis estilístico y técnico científico de un cabinet inédito de laca británica del siglo XVIII conservado en España". Ge-conservación n 13: 18-25.

ORELLANA, F. V. (1755). Tratado de barnices y charoles. Imprenta de Joseph García. Valencia.

PAOLINI, C. (2005). Glossario delle tecniche artistiche e del restauro. Edizioni Palazzo Spinelli. Florencia.

SÁNCHEZ CARO, I. (1866). El artista práctico. Manual que trata de pintura, dorado y plateado. Tipografía de don Juan Oliveres. Barcelona.

SANTINI, C. (2003). Le lacche dei Veneziani. Artioli. Módena.

SAYERS, R. (1762). The Ladies Amusemente, or the Whole Art of Japanning Made Easy. Londres, (Ed. cons. Newport, 1966): 25.

STALKER, J., PARKER, G. (1998) A treatise of jappaning and varnishing. 1668. Ed. cons. Alec Trianti. Reading.

VAN HAUWERMEIREN - ECHEMENT, C. (2008). "La découverte $\mathrm{d}^{\prime}$ une porte en lacca povera du XVIII siécle vénitien. Quand restauration s'associe avec dégradation". Ceroart, n 2, http:// ceroart.revues.org/495?lang=en (consulta 13. 4. 2019).

WATIN, J.F. (1766). L'art de faire et d'employer le vernis ou L'art du vernisseur, Durand París, 1772.

WEBB, M. (2000). Laquer: Technology and Conservation. Butterworth--Heinemann. Oxford.

WOLVESPERGES, T. (2000). Le meuble français en laque au XVIIle siecle. Editions Racine. Bruselas.

ZOTTI MINCI, C. A. (1994). Le stampe popolari dei Remondini. Neri Pozza. Vincenza.

\section{Autor/es}

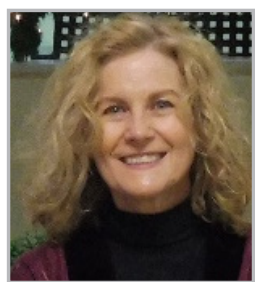

\section{Cristina Ordóñez Goded}

cristina @arcaz.com

Arcaz Restauración S.L

Doctora en Historia del Arte por la Universidad Complutense de Madrid con la tesis doctoral: De lacas y charoles en España. Siglos XVI-XIX. Premio extraordinario de doctorado 2017. Investigadora independiente. Conservadora-Restauradora de mobiliario. Socia fundadora de Arcaz Restauración S.L. Madrid.

www.arcaz.com

https://ucm.academia.edu/CristinaOrdo\%C3\%B1ez
Artículo enviado el 01/10/2019 Artículo aceptado el 17/12/2019

https://doi.org/10.37558/gec.v17i1.691 